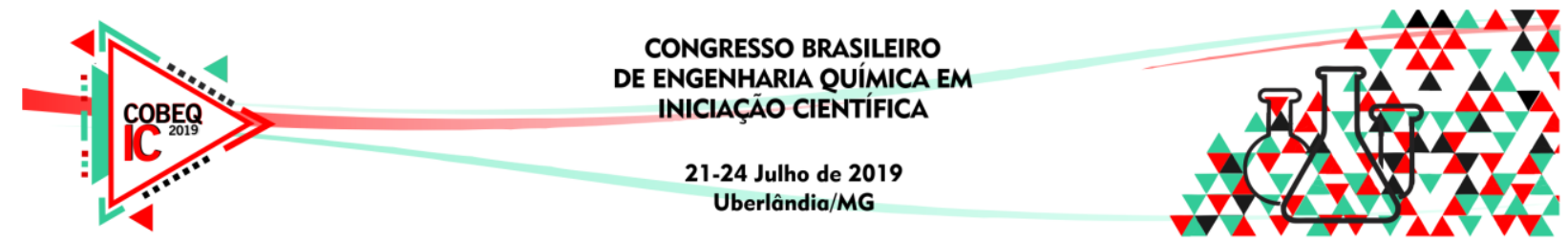

\title{
PIRÓlISE ANALÍTICA CATALÍTICA EX SITU DA CHLAMYDOMONAS REINHARDTII E CARACTERIZAÇÃO DO BIO-ÓLEO
}

\author{
I. H. N. MORAIS ${ }^{1}$, J. M. BARBOSA ${ }^{1}$, R. A. S. ROSSI ${ }^{1}$, M. A. S. BARROZO ${ }^{1}$ e L. G. M. \\ VIEIRA $^{1}$ \\ ${ }^{1}$ Universidade Federal de Uberlândia, Faculdade de Engenharia Química \\ E-mail para contato: iagohenrique@ufu.br
}

\begin{abstract}
RESUMO - Nas últimas décadas a busca por fontes renováveis de energia tem aumentado, visando minimizar os impactos ambientais causados pelos combustíveis fósseis. No contexto da produção de combustíveis renováveis, o biocombustível (bio-óleo) oriundo de algas tem se apresentado como alternativa promissora com potencial para atender a demanda global de combustíveis. A pirólise analítica é um processo de conversão baseado nas reações de degradação química induzidas por energia térmica na ausência de oxigênio, resultando em carvão, bio-óleo e gás, os quais estão relacionados à composição inicial da amostra. Os componentes presentes no bio-óleo são identificados por cromatografia gasosa acoplada a espectrometria de massa. Este trabalho investigou os efeitos da temperatura e do catalisador hidrotalcita nos produtos gerados a partir da pirólise analítica catalítica ex situ da microalga Chlamydomonas reinhardtii. A presença do catalisador (ex situ) favoreceu a qualidade do bio-óleo, pois aumentou a produção de hidrocarbonetos provenientes da degradação de lipídeos. O aumento da temperatura proporcionou reduções consideráveis nos compostos oxigenados, contribuindo para diminuir possíveis reações de oxidação, que são prejudiciais para os combustíveis renováveis.
\end{abstract}

\section{INTRODUÇÃO}

O demasiado crescimento populacional e econômico tem afetado significativamente a demanda energética global, aumentando de modo expressivo o consumo de produtos derivados do petróleo. Atualmente, estima-se que a participação de combustíveis fósseis na demanda global de energia atingiu cerca de $80 \%$, um nível que se manteve estável por mais de três décadas, mesmo com o forte crescimento de fontes alternativas de energia (IEA, 2017). Assim, com intuito de atender tal demanda e diminuir os impactos ambientais causados pela utilização desses combustíveis, cada vez mais se tem buscado fontes de energia renováveis como biomassa e energia solar.

De acordo com Marafon et al. (2016) a biomassa é uma matéria prima de baixo custo e fácil acesso, capaz de armazenar grande quantidade de energia, carbono, oxigênio e hidrogênio. Trata-se de uma das poucas fontes que pode facilitar a produção de energia em escala industrial. Ao contrário de outras fontes que são intermitentes, como as energias solar e 


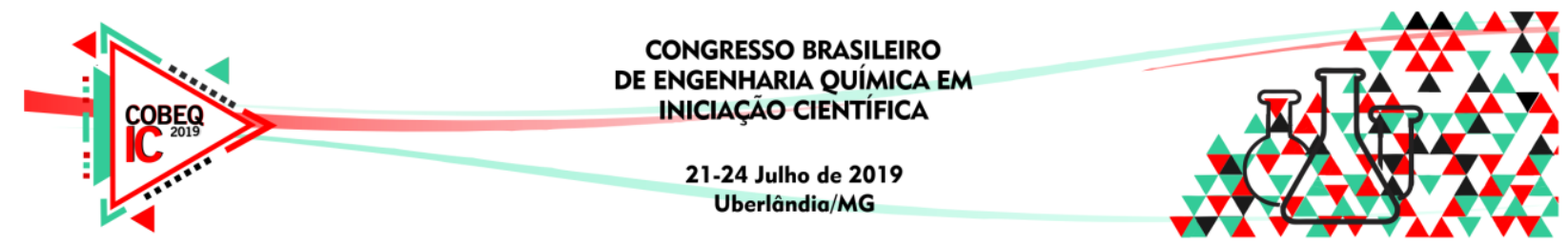

eólica, a energia obtida através da biomassa pode ser aproveitada a qualquer momento (Philippi Júnior e Reis, 2016).

No cenário mundial atual, a biomassa e a energia solar representam apenas uma pequena parcela do fornecimento de energia. Sendo que a biomassa contribui com apenas $10,6 \%$, das necessidades energéticas globais, enquanto que a energia solar representa menos de $1,7 \%$ do fornecimento de energia primária (Goldemberg e Lucon, 2007).

Segundo a Empresa de Pesquisas Energéticas, o Brasil é um dos países que mais utiliza fontes renováveis quando comparado ao resto do mundo. Somando lenha e carvão vegetal, energia hidráulica, derivados de cana e outras fontes renováveis, totalizam 42,9\%, quase metade da nossa matriz energética (EPE, 2019).

A utilização de microalgas como fonte de biomassa tem ganhado ênfase, pois possui diversas vantagens em comparação aos materiais lignocelulósicos: a produção de biomassa pode ser de 5 a 30 vezes maior do que a de oleaginosas por unidade de área; não competem por área com os recursos agrícolas, uma vez que podem ser cultivadas em terras não cultiváveis ou em águas residuais. Além disso, as microalgas são extremamente ricas em óleo, e algumas espécies são compostas por mais de $60 \%$ em peso de óleo em base seca (Du et al., 2011).

A pirólise é um processo em que ocorre a degradação térmica de materiais orgânicos, na ausência total ou parcial de oxigênio, convertendo-os em produtos químicos, dentre eles um líquido, chamado de óleo de pirólise ou bio-óleo (Santana Júnior, 2018).

A micropirólise ou pirólise analítica é uma metodologia rápida e eficaz que provê informações preliminares úteis para o desenvolvimento do processo complexo de produção de bio-óleo (Oliveira et al., 2015). A micropirólise também é usada para investigar a influência de catalisadores na qualidade do bio-óleo antes de se realizar experimentos em maior escala (Boateng et al., 2010).

Este trabalho investigou a influência da temperatura e do catalisador hidrotalcita nos produtos gerados a partir da micropirólise catalítica ex situ da microalga Chlamydomonas reinhardtii, bem como a composição do seu bio-óleo.

\section{MATERIAL E MÉTODOS}

\subsection{Microalga e catalisador}

A microalga Chlamydomonas reinhardtii foi adquirida da empresa Clover Nutrition S/A (Xi'an, China) com umidade de 6\% $\pm 0,03$.

$\mathrm{O}$ catalisador do tipo hidrotalcita $(\mathrm{Mg}-\mathrm{Al})$ foi sintetizado pelo método de coprecipitação com $\mathrm{pH}$ controlado $(\mathrm{pH}=10)$, segundo o método descrito por Cavani et al. (1991).

\subsection{Pirólise analítica catalítica}




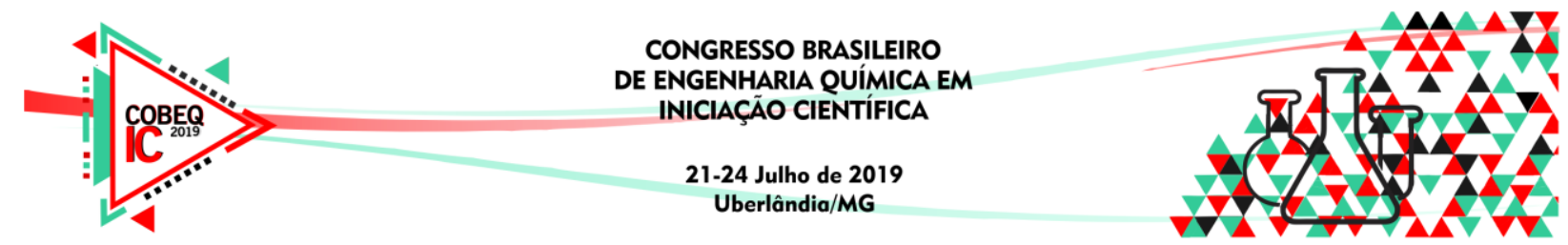

As análises da pirólise analítica foram realizadas no micropirolisador Pyroprobe 5200 da CDS Laboratório de Processos de Separação da Faculdade de Engenharia Química da Universidade Federal de Uberlândia.

Os testes foram executados com e sem o catalisador, a fim de investigar os efeitos causados pela presença do mesmo. Para os testes catalíticos foi usada uma razão de catalisador/biomassa de 1:2, e a microalga e o catalisador foram colocados em compartimentos separados no micropirolisador conforme a técnica catalítica ex situ. O gás hélio com alta pureza $(99,999 \%)$ foi utilizado como gás de arraste e a taxa de aquecimento utilizada foi de $20^{\circ} \mathrm{C} \cdot \mathrm{ms}^{-1}$. As temperaturas de reação foram de $450,550,650$ e $750^{\circ} \mathrm{C}$.

Os produtos obtidos da pirólise foram analisados por cromatografia gasosa e espectrometria de massa (sistema Shimadzu QP 2010 Plus GC/MS). A coluna Rxi-1ms de 30 $\mathrm{m}$ de comprimento, $0,25 \mathrm{~mm}$ de diâmetro e espessura da película de $0,25 \mu \mathrm{m}$ foi utilizada para separar os componentes dos vapores. A fonte de ionização foi programada para operar com energia de ionização de $70 \mathrm{eV}$ a uma temperatura de $250^{\circ} \mathrm{C}$. Os compostos foram identificados com um índice de similaridade superior a $80 \%$ de acordo com o banco de dados da biblioteca NIST (versão 05).

\section{RESULTADOS E DISCUSSÃO}

\subsection{Efeito do catalisador ex situ na qualidade do bio-óleo}

A Figura 1 representa as porcentagens relativas das áreas dos picos cromatográficos considerando as frações dos componentes identificados em $100 \%$ da amostra injetada. As análises foram realizadas em diferentes condições, com e sem catalisador nas temperaturas estudadas. Os compostos obtidos foram classificados em oxigenados, fenóis, hidrocarbonetos alifáticos e aromáticos, e nitrogenados.

Figura 1 - Compostos identificados a partir da análise cromatográfica (GC/MS).
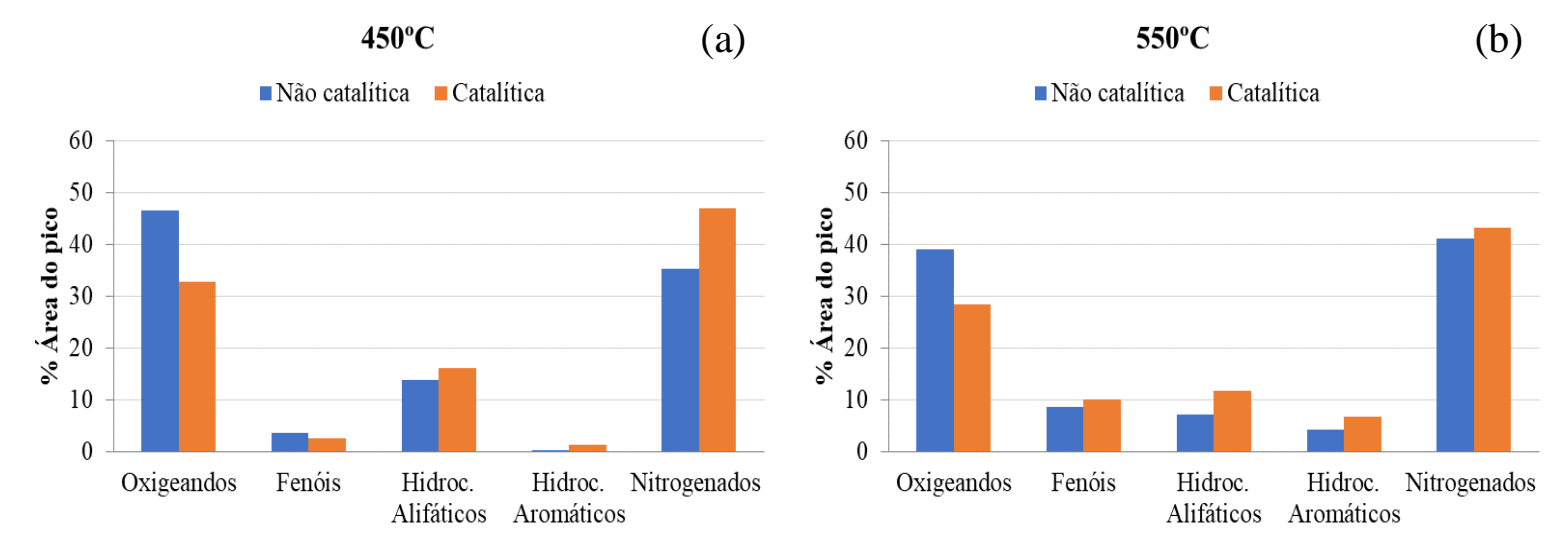

(b) 

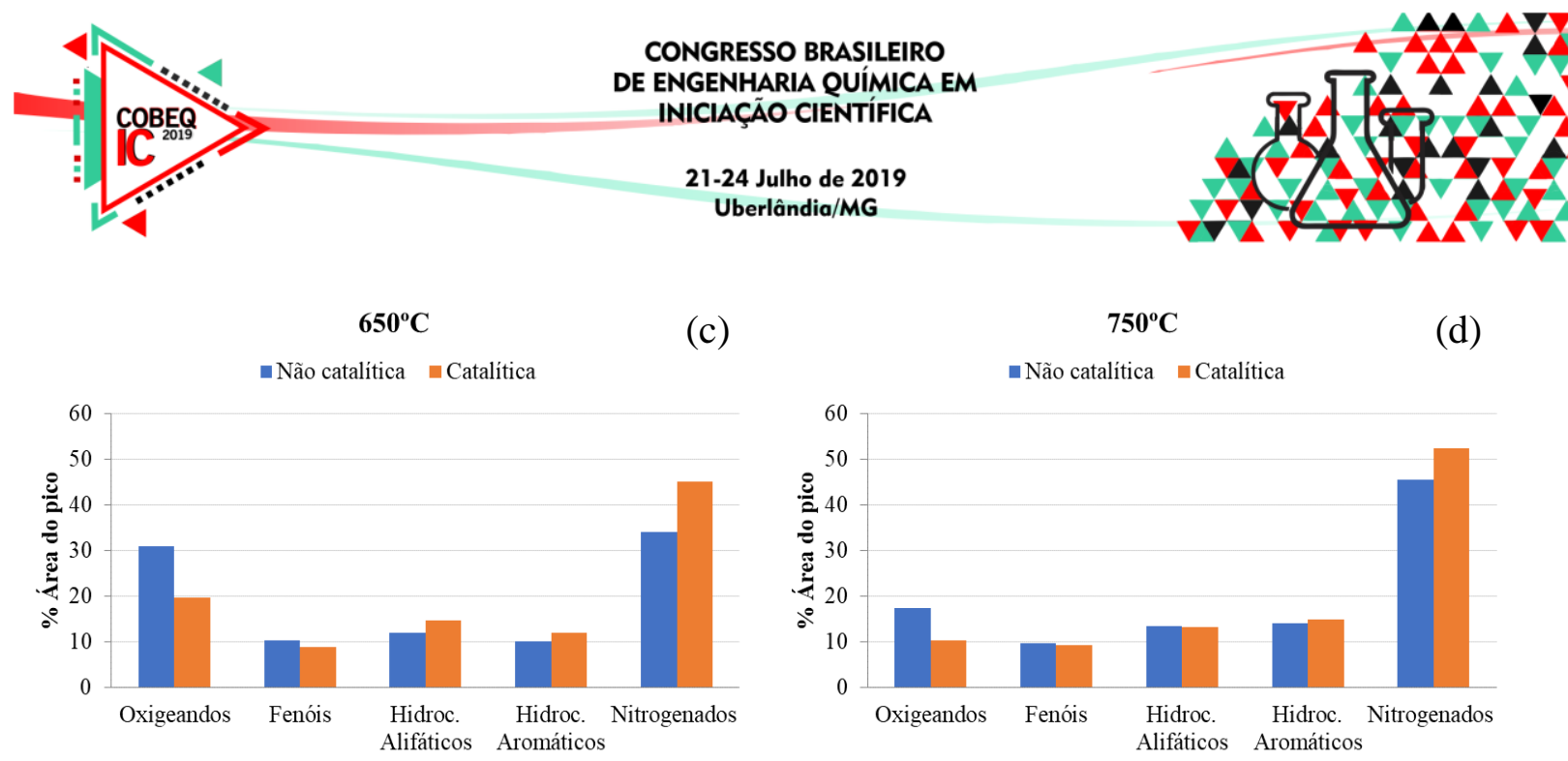

Com relação aos compostos oxigenados, notou-se que com a presença do catalisador houve uma diminuição no conteúdo desses compostos em todas as temperaturas examinadas. Essa diminuição foi inferior nas temperaturas mais elevadas. Segundo Chagas (2016), o bioóleo com elevado teor de oxigênio é indesejável para aplicações no setor produtivo de combustível devido as possíveis reações de oxidação que acabam tornando-o instável. Assim, a presença dos compostos oxigenados, causa efeito negativo no bio-óleo para fins combustíveis.

Para os compostos fenólicos e nitrogenados, nenhuma tendência clara foi observada. A presença de compostos oxigenados e nitrogenados, mostra que pode haver necessidade de aumento da porcentagem de catalisador em relação à biomassa considerando que muitos trabalhos utilizaram maiores razões de catalisador/biomassa como 5:1 e 10:1 (Chagas et al., 2016; Wang et al., 2014a; Bianchini et al., 2017). Outra opção seria realizar estudos com diferentes catalisadores.

Pode-se observar que os hidrocarbonetos alifáticos foram encontrados em maior quantidade do que os hidrocarbonetos aromáticos para todas as temperaturas, exceto para $750^{\circ} \mathrm{C}$. Além disso, a utilização do catalisador na configuração ex situ melhorou a seletividade para a formação de hidrocarbonetos alifáticos e aromáticos para as temperaturas estudadas, sendo mais pronunciado na temperatura de $550^{\circ} \mathrm{C}$ e menos pronunciado na temperatura de $750^{\circ} \mathrm{C}$. Segundo $\mathrm{Na}$ et al. (2015) a formação de hidrocarbonetos de cadeia longa bem como de ácidos e ésteres está associada à degradação de lipídeos constituintes do bio-óleo.

Wang et al. (2014b) que também estudaram a pirólise catalítica ex situ, observaram que os hidrocarbonetos aromáticos produzidos foram enriquecidos e se tornaram os compostos mais abundantes, com a presença do catalisador. Afirmaram ainda que os hidrocarbonetos aromáticos são considerados como produtos desejáveis para a indústria de biocombustíveis, já que eles não apenas têm um bom conteúdo volumétrico de energia, mas também têm uma grande influência positiva na vedação, adesivos, etc. em sistemas de motores a jato.

\subsection{Efeito da temperatura na qualidade do bio-óleo}

A Figura 2 apresenta os dados da pirólise catalítica ex situ. Os compostos oxigenados apresentaram uma tendência decrescente com o aumento da temperatura. Este aumento favorece a produção de gases com $\mathrm{CO}$ e $\mathrm{CO}_{2}$ que diminui a presença de compostos 


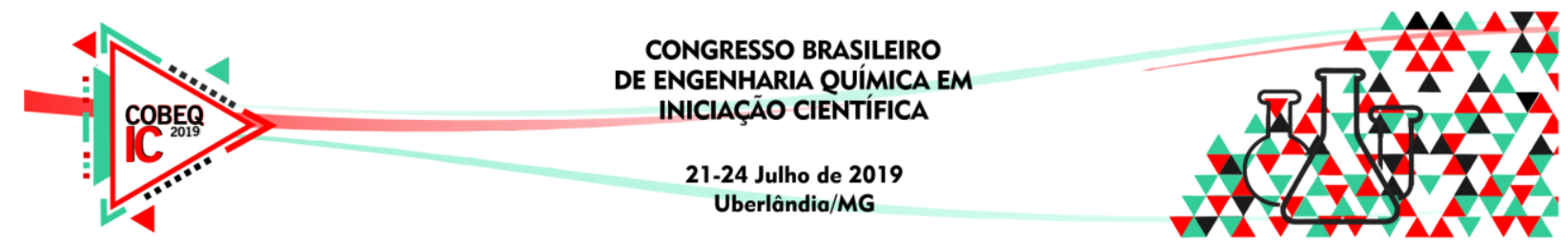

oxigenados na fase líquida (bio-óleo). Já os compostos fenólicos não apresentaram relação direta com a temperatura.

Figura 2 - Efeito da temperatura nos compostos encontrados na pirólise catalítica ex situ.
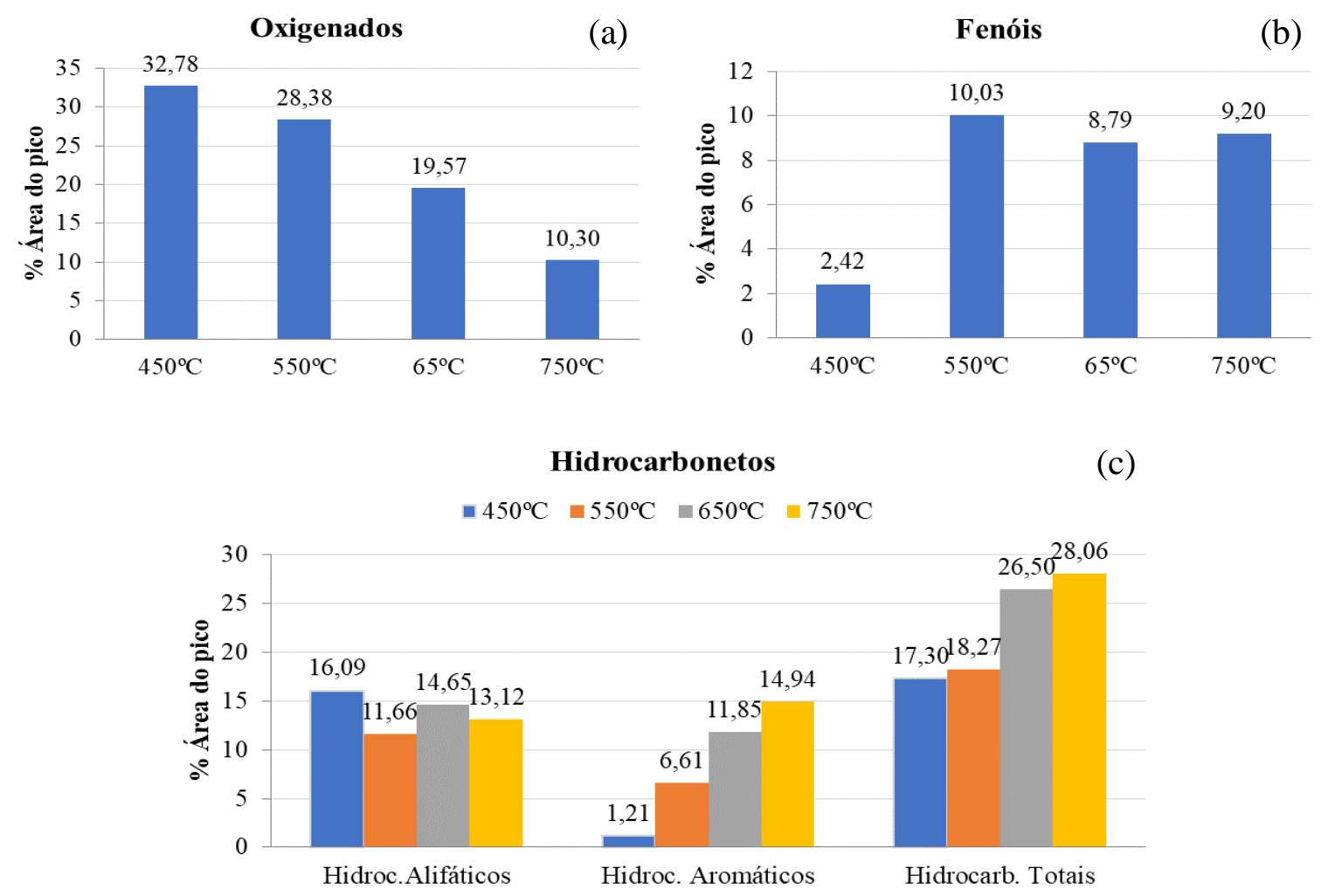

Pode-se observar uma formação expressiva de hidrocarbonetos alifáticos que não sofreram influência da temperatura. A quantidade de hidrocarbonetos totais cresceu com o aumento da temperatura, conforme mostra a Figura 2. Este aumento ocorreu principalmente devido a maior formação de hidrocarbonetos aromáticos que passou de 1,21\% para 14,945\% como observado também nos trabalhos de Andrade et al. (2018). Isto configura uma característica muito promissora da biomassa estudada para a produção de bio-óleo de alta qualidade. Visto que a pirólise não catalítica apresentou a mesma tendência com a variação da temperatura, os dados não foram apresentados.

\section{CONCLUSÃO}

O trabalho possibilitou investigar os efeitos da temperatura e do catalisador hidrotalcita nos produtos gerados a partir da pirólise analítica catalítica ex situ da microalga Chlamydomonas reinhardtii, bem como a qualidade do seu bio-óleo. Os resultados da pirólise catalítica mostraram que o aumento da temperatura contribuiu para aumentar a quantidade de hidrocarbonetos e diminuir a formação dos compostos oxigenados. Os óxidos mistos derivados da hidrotalcita melhoraram a qualidade do bio-óleo, porém a temperatura apresentou maior contribuição para o aumento considerável de hidrocarbonetos aromáticos.

\section{REFERÊNCIAS}




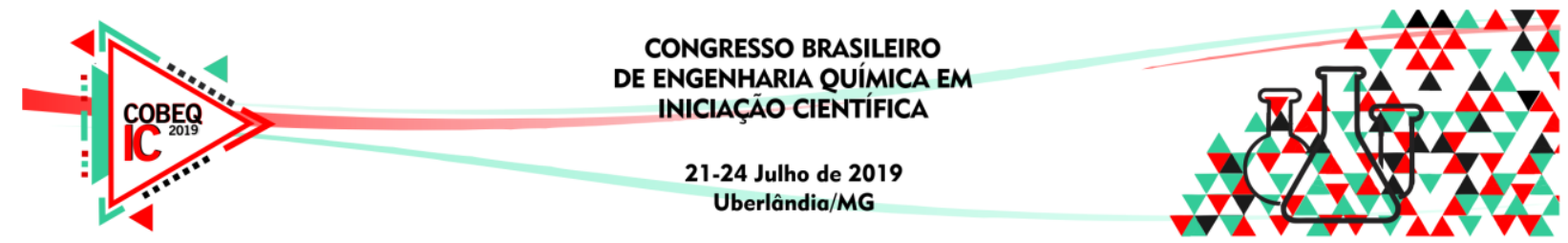

ANDRADE, L. A. Pirólise solar catalítica de microalgas. 2018. 135 p. Tese (Doutorado em Engenharia Química) - Universidade Federal de Uberlândia, Uberlândia, 2018.

BOATENG, A. A.; MULLEN, C. A.; MCMAHAN, C. M.; WHALEN, M. C.; CORNISH, K. Guayule (Parthenium argentatum) pyrolysis and analysis by PY-GC/MS. J. of Anal. and Appl. Pyrolysis, v. 87, n. 1, p. 14-23, 2010.

CAVANI, F.; TRIFFIRÒ, F.; VACCARI, A. Hydrotalcite-type Anionic Clays: Preparation, Properties and Applications. Catalysis Today. v.11, n.2, p.173-186, 1991.

CHAGAS, B. M. E. Pirólise rápida da cianobactéria Spirulina para produção de biocombustíveis e químicos. 2016. 138 p. Tese (Doutorado em Engenharia Química) Universidade Federal do Rio Grande do Norte, Natal, 2016.

DU, Z.; LI, Y.; WANG, X.; WAN, Y.; CHEN, Q.; WANG, C.; LIN, X.; LIU, Y.; CHEN, P.; RUAN, R. Microwave-assisted pyrolysis of microalgae for biofuel production, Bio. Technol., v. 102, p. 4890-4896, 2011.

EPE. Empresa de Pesquisa Energética. EPE, 2019. Disponível em: < http://epe.gov.br/pt/abcdenergia/matriz-energetica-e-eletrica>. Acesso em maio de 2019.

GOLDEMBERG, J.; LUCON, O. Energy and environment in Brazil. Estud. av., São Paulo, v. 21, n. 59, p. 7-20, 2007.

IEA. Global Energy \& CO2 Status Report. IEA, 2017. Disponível em: $<$ https://www.iea.org/geco/>. Acesso em março de 2019.

MARAFON, A. C.; SANTIAGO, A. D.; AMARAL, A. F. C.; BIERHALS, A. N.; PAIVA, H. L.; GUIMARÃES, V. S. Uso da biomassa para a geração de energia. Aracaju: Embrapa Tabuleiros Costeiros, 28 p., 2016.

NA, J.; PARK, Y.; KIM, DI.; OH, Y.; JEON, S. G.; KOOK, J. W. Rapid pyrolysis behavior of oleaginous microalga, Chlorella sp. KR-1 with different triglyceride contents. Renew Energy. v. 81, p.779-784, 2015.

OLIVEIRA, T. J. P.; CARDOSO, C. R.; ATAÍDE, C. H. Fast pyrolysis of soybean hulls: analysis of bio-oil produced in a fluidized bed reactor and of vapor obtained in analytical pyrolysis. J. of Therm. Anal. and Calorimetry, v. 120, n. 1, p. 427-438, 2015.

PHILIPPI JÚNIOR, A.; REIS, L. B. Energia e sustentabilidade. Barueri: Editora Manole, v. 19, 1021 p., Coleção Ambiental, 2016.

SANTANA JÚNIOR, J. A. Efeito catalítico de zeólita ZSM-5 e ácido nióbico HY-340 na pirólise e hidropirólise de ligninas kraft industriais. 2018. 116 f. Tese (Doutorado em Engenharia Química) - Universidade Federal de Uberlândia, Uberlândia, 2018.

WANG, K.; JOHNSTON, P. A.; BROWN, R. C. Comparison of in-situ and ex-situ catalytic pyrolysis in a micro-reactor system. Bioresource Technology, v. 173, p. 124-131, 2014. (a)

WANG, L.; LEI, H.; BU, Q.; REN, S.; WEI, Y.; ZHU, L.; ZHANG, X.; LIU, Y.; YADAVALLI, G.; LEE, J.; CHEN, S.; TANG, J. Aromatic hydrocarbons production from ex situ catalysis of pyrolysis vapor over Zinc modified ZSM-5 in a packed-bed catalysis coupled with microwave pyrolysis reactor. Fuel. v.129, p.78-85, 2014. (b) 